\title{
Risk Factors for Depressive Illness among Elderly Gopd Attendees at Upth
}

\author{
Princewill Stanley \\ 1. Onya, O N - Dept. of Family Medicine, UPTH, Port Harcourt, Nigeria \\ 2. Stanley, PC-Dept. of Mental Health, UPTH, Port Harcourt, Nigeria
}

\begin{abstract}
Background: Depression among the elderly is associated with very high morbidity and suicide rates. In view of the fact that this cohort of patients often have concomitant psychosocial and biomedical health concerns it would be of interest to determine the risk factors for developing this debilitating illness.

Objective: To determine the risk factors for depressive illness among elderly patients attending the GOPD of UPTH.

Materials and Methods: A descriptive cross-sectional study was conducted among 150 elderly GOPD attendees at UPTH, Nigeria. The respondents completed a structured interviewer-administered questionnaire containing the Geriatric Depression Scale (a depression screening tool).

Results: The male to female ratio was 1:1.5. Most of the patients fell into the 65-69 year age group. The men were significantly more educated than the women. 42 (28\%) of the patients were found to be depressed. 34 (80.9\%) of them were female. This difference was statistically significant. In addition, older age groups, urban dwelling (especially with children), poor family support, marital disharmony, widowhood, bereavement, poor educational background and low social status were found to be risk factors for depressive illness in the elderly. Prior history of depression, stressful life events, regular usage of antidepressant drugs, antihypertensives, antidiabetic and anti oncotic agents were also found to be risk factors. Ironically, unemployment and living alone were not found to be risk factors.

Conclusion: The risk factors for geriatric depression are many and varied and are substantially in keeping with findings made by other investigators previously. However, there are peculiarities which could be accounted for by the socio-economic situation and cultural values in the study environment.
\end{abstract}

\section{INTRODUCTION}

Depression worldwide is a major cause of morbidity commonly associated with a decline in social, occupational and interpersonal functioning ${ }^{1}$. Worse still the liability of this dreaded psychological condition often worsened by environmental and physical factors increases with age. Hence the elderly appear to suffer the impact much more than people in other age groups. Therefore, it would be a rewarding scientific adventure to have an insight into the possible risk factors for depression among the elderly in our environment.

However, based on previous studies, risk factors for depressive illness in the elderly can be grouped into psychosocial, biological, personality characteristics, medications and socio-demographic factors.

Psychosocial factors include stressful life events eg bereavement, financial failures, loneliness etc. ${ }^{2,3}$ Previous history of depression or anxiety is also a psychosocial risk factor ${ }^{3,4}$.

Biological/genetic factors include: female gender, folate and vitamin B12 deficiency, ${ }^{5}$ "vascular depression" where stroke is implicated, ${ }^{6,7,8}$ and chronic or severe physical pain. ${ }^{9}$

Personality traits include: low self esteem, extreme dependency and pessimism.

Medications include: anxiolytics, tranquilizers, anti inflammatory, anti-infective agents, beta and clcium channel blockers, hormonal agents, cardiotonic drugs and alcohol.

Finally, low socio-economic status, poor educational background and widowhood are sociodemographic factors associated with depression in the elderly. ${ }^{10,11,12}$.

It is worthy of note that exercise has been shown to improve depressive symptoms and overall health outcomes in elderly patients with depressive illness. ${ }^{12,13,14,15}$

Depressive illness in the elderly may be complicated by co- morbid general medical conditions which frequently plague them and they present with an array of somatic symptoms that may be attributable to the co-existing conditions individually or collectively $\mathrm{y}^{16}$.

As many as $46 \%$ of elderly depressed patients have co-morbid physical diagnoses. Conversely, elderly physically ill patients frequently show symptoms of depression. This may be transient but in some cases can persist interfering with social functioning and impairing recovery from the physical illness itself. ${ }^{17,18}$

There are several general medical conditions associated with depression:

The aetiology of depression in diabetes mellitus is still poorly understood ${ }^{19,20}$, but results from several, predominantly cross-sectional studies suggest the onset of depression in diabetes is associated with not only 
socio-demographic factors such as female sex, living alone and low income, but also with diabetes relatedfactors such as poor glycaemic control and the presence of diabetic complications. Research suggests not only a higher prevalence but also a higher recurrence rate of depression among diabetics. ${ }^{21}$

Other general medical conditions associated with depression include: cancer, ${ }^{22}$ stroke, ${ }^{20}$ coronary artery disease, ${ }^{23,20}$ alzheimer's disease, ${ }^{24}$. myocardial Infarction, alcohol abuse, Huntington's disease, heart failure, ${ }^{25}$ and Chronic Obstructive Pulmonary Disease (COPD) ${ }^{23}$

Furthermore, severe anaemia, thyroid disease and malignancies could mimic depressive illness. Symptoms such as lack of energy, poor concentration and weight loss may be due to physical illness or ageing, not depression and this poses a challenge even to the most experienced clinicians. In order to circumvent these difficulties, rating scales can be used.

In addition, these coexisting medical conditions have been shown to worsen the morbidity accounted for by depression and vice versa. ${ }^{26}$ Gazmararian et al found an association between increasing numbers of (at least two) chronic conditions and increased depressive symptomatology. ${ }^{27}$

Worthy of note is the fact that cultural factors immensely contribute to the symptomatology of depressive illness. $^{28}$

It is chiefly due to this masking of depressive symptoms by somatic complaints which in some cases could be attributed to somatization disorder, or cognitive impairment that the diagnosis of depressive illness in the elderly patients attending the General Outpatient Department very often eludes the Family Physician. Yet the majority of elderly depressed patients are seen by Family Physicians. ${ }^{29}$

In view of this, depression in late life remains a difficult but very important clinical challenge for Family Physicians the world over. ${ }^{29,30}$

Ultimately, this leads to increased consultation rates which may be an indicator to the presence of under-diagnosed or misdiagnosed clinical conditions including depression. ${ }^{31}$

Another issue of utmost concern to the Family Physician is the unnecessary and often colossal financial burden this over utilization of health care services poses to both the nuclear and extended families who in our environment are more often than not the caregivers. Thus a high index of suspicion is required to arrive at the diagnosis of depressive illness in the elderly.

It is important to stress that the aetiology of depression in the elderly is multifactorial, its presentation may be atypical and treatment is complex in that it involves consideration of the role of co-morbidities, cognitive changes, concomitant medication and the status of the patients' support systems. If not detected early, it presents a significant risk factor for suicide. ${ }^{32,33}$

In our environment, there is paucity of information about the risk factors for depression in this cohort of individuals in spite of its debilitating nature in this age group, hence the need for this study.

It is of utmost importance to take into consideration the psychological, socio-cultural and spiritual concerns of the elderly patients in line with the biopsychosocial model ${ }^{34}$ with a view to providing holistic continuing and comprehensive care in the context of their families and their socio-cultural environment.

\section{MATERIALS AND METHODS}

A descriptive cross-sectional study was conducted among men and women 65 years and older attending the GOPD of UPTH, Rivers State, Nigeria between August and September 2007. 150 of this cohort of patients that met the inclusion criteria were recruited for the study.

The geriatric patients are seen by both the consultants and residents in the Family Medicine department. An average of 500 elderly patients is seen monthly representing over $25 \%$ of the total number of patients seen at the GOPD every month. There are 20 working days in each month and therefore an average of about 25 elderly patients are seen each working day.

In order to conduct the study within the 2-month time frame and to avoid bias, a systematic random sampling technique was used and every $5^{\text {th }}$ patient who met the inclusion criteria was recruited giving a total number of 5 patients every working day until the desired number of subjects were obtained for the study.

On recruitment, each patient underwent a clinical evaluation and a structured questionnaire was administered to them by the interviewer. Relevant laboratory investigations were requested in some cases to detect co-morbid medical illnesses and ascertain the significance of somatic complaints. The questionnaire had the following components: Socio-demographic data; The socio-economic status of the patients was assessed using Oyedeji's social classification, current clinical diagnosis, regularly used drugs, past history of depression and the Geriatric Depression Scale.

Ethical approval and informed consent were obtained from the hospital ethical committee and the subjects, respectively. Those who declined consent were allowed to withdraw and this did not diminish their rights and privileges to be cared for.

Those found to be depressed were managed appropriately. 
1. The Geriatric Depression Scale

\section{RESULTS}

The Geriatric Depression Scale was the tool used for diagnosing depression in the respondents. The prevalence of depression among the respondents was calculated based on the G.D.S. scores obtained.

Figure 1 shows the prevalence of depression among the respondents.

Scores ranged from 2-20. The mean score was 8.6+4.2; the median was 8.0 and the mode was 5.0. Thirty two (22\%) patients scored 10 and above but less than 18 (i.e. mildly to moderately depressed) on the Geriatric Depression Scale, while 9 (6\%) scored 18 and above (i.e. severely depressed). This gives a total depression prevalence of $28 \%$ (figure 1).

\section{Figure 1: Prevalence of Depression among the Respondents}


Table 1: Distribution of the Socio-Demographic Characteristics of the Studied Population and Relationship with Depression

\begin{tabular}{|c|c|c|c|c|c|}
\hline $\begin{array}{l}\text { Age Distribution } \\
\text { (age group in } \\
\text { years) }\end{array}$ & $\begin{array}{l}\mathrm{N}(\%) \\
\text { Male } \\
\text { Depressed(\%) } \\
\text { female }\end{array}$ & $\begin{array}{r}\text { Female } \\
\text { Both male \& }\end{array}$ & Total & $\mathbf{x 2}$ & p value \\
\hline $\begin{array}{l}65-69 \\
70-74 \\
75-79 \\
80-84\end{array}$ & $\begin{array}{ll}51(86 \%) & 65(71 \%) \\
5(8.5 \%) & 15(16.5 \%) \\
2(3.4 \%) & 8(8.8 \%) \\
1(1.7 \%) & 3(3.3 \%)\end{array}$ & $\begin{array}{l}24(20.7) \\
6(30.0) \\
\quad 8(80.0) \\
4(100)\end{array}$ & $\begin{array}{l}116 \\
20 \\
10 \\
4\end{array}$ & 26.831 & 0.000 \\
\hline $\begin{array}{l}\text { Gender } \\
\text { Distribution }\end{array}$ & $\begin{array}{l}\text { Not } \\
\text { Depressed(\%) }\end{array}$ & Depressed(\%) & $\begin{array}{l}\text { Total } \\
\text { value }\end{array}$ & $\mathbf{x 2}$ & $\mathbf{p}$ \\
\hline $\begin{array}{l}\text { Male } \\
\text { Female }\end{array}$ & $\begin{array}{l}51(86.4) \\
57(62.6)\end{array}$ & $\begin{array}{l}8(13.7) \\
34(37.4)\end{array}$ & $\begin{array}{l}59 \\
91 \\
0.002\end{array}$ & & 10.060 \\
\hline Ethnic Group & $\begin{array}{l}\text { Not } \\
\text { Depressed }(\%)\end{array}$ & Depressed(\%) & $\begin{array}{l}\text { Total } \\
\text { value }\end{array}$ & $\mathbf{x 2}$ & $\mathbf{p}$ \\
\hline $\begin{array}{l}\text { Igbo } \\
\text { Ikwerre/Etche } \\
\text { Ijaw } \\
\text { Ogoni } \\
\text { Other } \\
\text { groups }\end{array}$ & $\begin{array}{l}53(82.8) \\
20(60.6) \\
17(100) \\
7(63.6) \\
11(44.0)\end{array}$ & $\begin{array}{l}11(6.2) \\
13(39.4) \\
0(0.0) \\
4(36.4) \\
14(56.0)\end{array}$ & $\begin{array}{l}64 \\
33 \\
17 \\
0.000 \\
11 \\
25\end{array}$ & & 22.552 \\
\hline Marital Status & Not Depressed(\%) & Depressed(\%) & $\begin{array}{l}\text { Total } \\
\text { value }\end{array}$ & $\overline{x 2}$ & $\mathbf{p}$ \\
\hline Widowed & $49(63.6)$ & $28(36.4)$ & 77 & & 5.490 \\
\hline
\end{tabular}


Risk Factors for Depressive Illness among Elderly Gopd Attendees at Upth

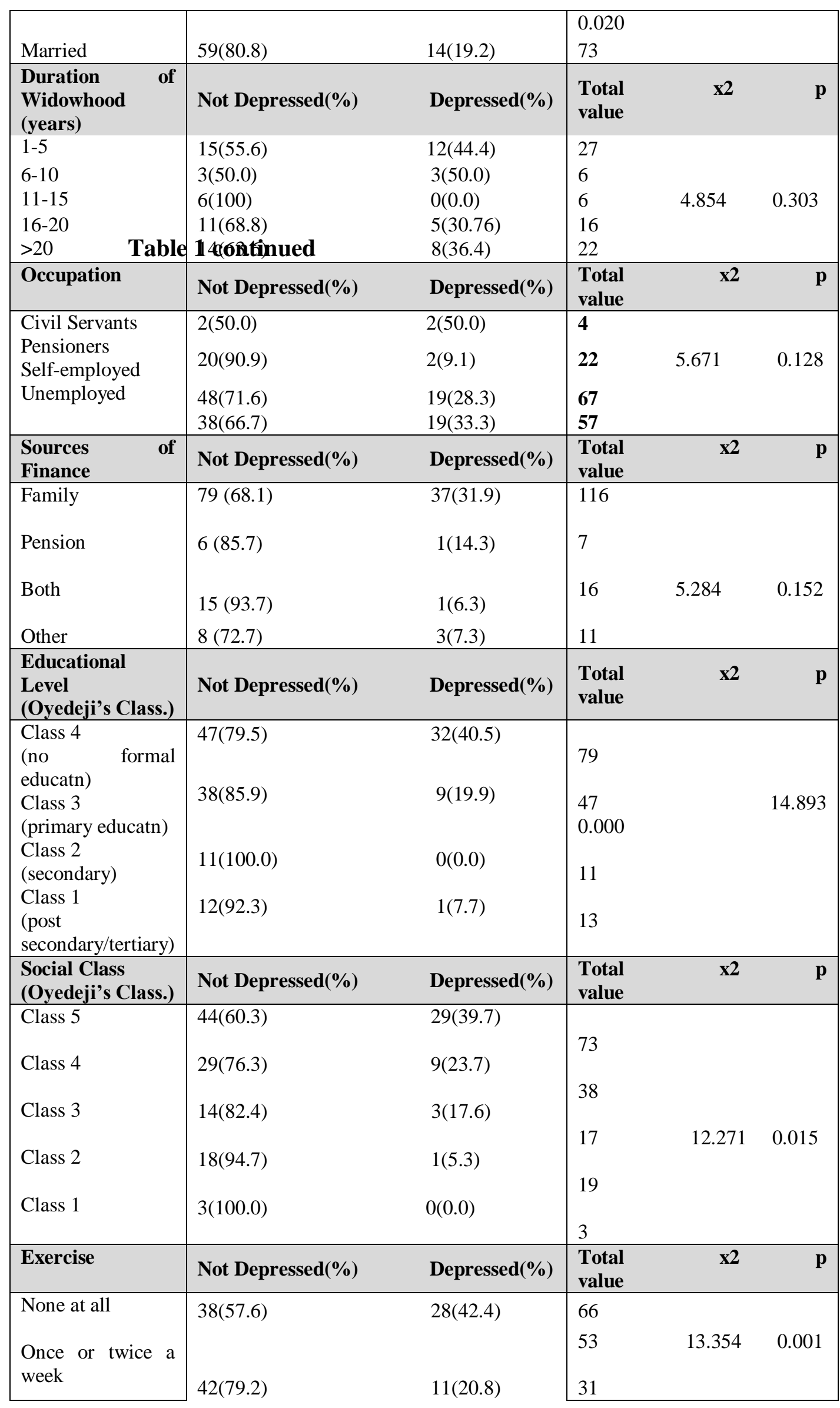




\begin{tabular}{|l|l|l|}
\hline $\begin{array}{l}3 \text { or more times a } \\
\text { week }\end{array}$ & 28(90.3) & $3(9.7)$ \\
\hline
\end{tabular}

\section{Relationship between Socio- Demographic Characteristics and Depression}

Table 1 shows the relationship between the age-groups, ethnicity, marital status, duration of widowhood, occupation, sources of finance, educational level, social class and frequency of exercise of the respondents and depression.

It highlights the fact that there is a significant association between increasing age and prevalence of depression $\left(\mathrm{x}^{2}-26.813, \mathrm{df}=6\right.$; $\left.\mathrm{p}-0.000\right)$.

Significantly more females $(37.4 \%)$ than males $(13.7 \%)$ were found to be depressed $\left(x^{2}=10.060 ; \mathrm{df}=2 ; \mathrm{p}=0.002\right)$

The distribution of marital status among the subjects is also clearly illustrated. About $36.4 \%$ of widowed patients as against $19.2 \%$ of those whose spouses were still alive, were depressed. Therefore, widows and widowers have a significantly higher prevalence of depression than those whose spouses were still alive $\left(\mathrm{x}^{2}=5.490 ; \mathrm{df}=2 ; \mathrm{p}=0.0\right.$

Table 1 also shows that the prevalence of depression increases with the duration of widowhood and reaches a peak in the first ten years. Thereafter, the prevalence drops and peaks again in those who had been widowed for $>20$ years. These differences are not statistically significant $\left(\mathrm{x}^{2}=4.854 ; \mathrm{df}=4 ; \mathrm{p}=0.303\right)$.

The table shows that those that belonged to the Ijaw and Igbo ethnic groups had a lower prevalence of depression than the Ikwerre/Etche and the Ogoni ethnic groups. Specifically, none of the Ijaw respondents were depressed while the Ikwerre/Etche had the highest (39.4\%) prevalence of depression (excluding the "other" ethnic groups). These differences are statistically significant $\left(\mathrm{x}^{2}=22.552 ; \mathrm{df}=4 ; \mathrm{p}=0.000\right)$.

The relationship between the occupation of the respondents and depression is clearly elucidated in Table 1:

Fifty percent of civil servants, $33 \%$ of those unemployed, $28.3 \%$ of those self-employed and $9.1 \%$ of the pensioners were found to be depressed. This is illustrated in table 8 . However, no statistically significant association was found between occupation and prevalence of depressive illness. $\left(\mathrm{x}^{2}=5.671 ; \mathrm{df}=3 ; \mathrm{p}=0.128\right)$. Chi square for trend shows that civil servant carries an odds ratio of 10 which is the highest risk, followed by unemployment with 5, then self-employment with 3.96 and pensioner with 1 .

Table 1 also shows the relationship between the educational levels attained by the respondents depression. Those with no formal education constitute the group with the highest prevalence of depression (32 out of 79 i.e. $40.5 \%$ ). This is followed by those with only primary school education ( 9 out of 47 i.e. $19.1 \%$ ). Thus there is a significant association between the level of education of the respondents and depression. $\left(\mathrm{x}^{2}=14.893 ; \mathrm{df}=3 ; \mathrm{p}=0.000\right)$.

The table shows the relationship between the social classes of the respondents and prevalence of depression. Social class 5 accounts for the majority of those diagnosed as being depressed. Out of the 38 patients in social class 4, $9(23.7 \%)$ were depressed.

Only $1(5.3 \%)$ patient in social class 2 was depressed, while no patient in social class 1 was depressed. This is illustrated in table 10. Thus those in social classes 4 and 5 had a higher prevalence of depression and this difference is statistically significant $\left(\mathrm{x}^{2}=12.271 ; \mathrm{df}=4 ; \mathrm{p}=0.015\right)$.

The relationship between the sources of finance of the respondents and depression among them is clearly shown in Table 1:There was no association between the sources of finances of the subjects in this study and depression $\left(\mathrm{x}^{2}=5.284 ; \mathrm{df}=3 ; \mathrm{p}=0.152\right)$.

Table 1 shows the relationship of the frequency of exercise with depression. Those that exercised regularly had the lowest prevalence of depression (3 out of 31 i.e.9.7\%). Incidentally this group formed the minority ( 31 out of 150 i.e. $20.67 \%$ ).

The majority of the patients never exercised and this group had the highest prevalence of depression 28 out of $66(42.4 \%)$. Lower frequency of exercise is therefore significantly associated with increased prevalence of depression. $\left(\mathrm{x}^{2}=13.354 ; \mathrm{df}=2 ; \mathrm{p}=0.001\right)$.

\section{Relationship between Regularly Used Drugs and Depression}

Table 2 shows the relationship between regularly used drugs and depression among the respondents. Out of the regularly used drugs, antidepressants $(x 2=10.711 ; p=0.005)$, antihypertensives $\left(x^{2}=6.839 ; p=0.033\right)$, anti cancer agents $\left(\mathrm{x}^{2}=8.722 ; \mathrm{p}=0.013\right)$, and antidiabetic agents $\left(\mathrm{x}^{2}=6.139 ; \mathrm{p}=0.046\right)$ were significantly associated with a higher prevalence of depression (table17). 
Table 2: Relationship between Regularly Used Drugs and Depression

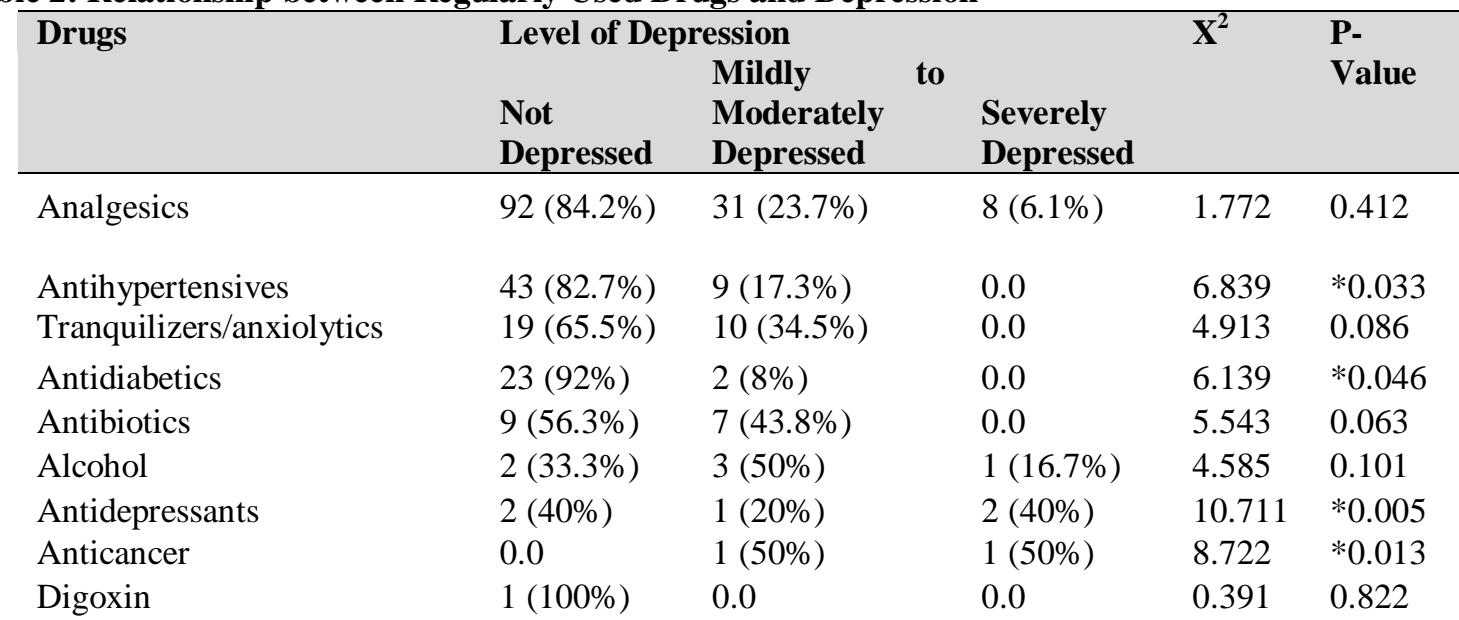

N.B. Some of the respondents took more than one drug.

\section{Relationship between Prior History of Depression Depression}

Table 3 shows the relationship between prior history of depression and depression.

Only 20 out of $119(16.8 \%)$ patients shown in table 14 without a prior history of depression were depressed, while 22 out of $31(71 \%)$ with a prior history of depression, were depressed. Out of this number, $7(22.6 \%)$ were severely depressed. Therefore prior history of depression is significantly associated with a higher prevalence of $\operatorname{depression}\left(\mathrm{x}^{2}=40.291 ; \mathrm{df}=2 ; \mathrm{p}=0.000\right)$.

None of the subjects admitted to having a family history of depression.

Table 3: Relationship between Prior History of Depression and Depression

\begin{tabular}{lllll}
\hline Prior History of depression & Prevalence of Depression & \multicolumn{2}{c}{ Total } \\
& Mildly & Moderately & to & Severely \\
& Depressed & Depressed & Depressed & \\
\hline No & $99(83.2)$ & $18(15.1)$ & $2(1.7)$ & $\mathbf{1 1 9}$ \\
Yes & $9(29.0)$ & $15(48.4)$ & $7(22.6)$ & $\mathbf{3 1}$ \\
\hline Total & $\mathbf{1 0 8}$ & $\mathbf{3 3}$ & $\mathbf{9}$ & $\mathbf{1 5 0}$ \\
\hline P-Value & $\mathbf{0 . 0 0 0}$ & & & \\
\hline $\boldsymbol{X}^{2}$ & $\mathbf{4 0 . 2 9 1}$ & & & \\
\hline
\end{tabular}

\section{Relationship between Stressful Life Events and Prevalence of Depression}

Table 4 shows the relationship between stressful life events and the prevalence of depression. It shows that those who had experienced stressful life events had a greater prevalence of depression than those that had not. 108 patients had had stressful life events while 42 had not. Out of the former, $32(29.6 \%)$ were mildly to moderately depressed. $8(7.4 \%)$ out this number were severely depressed. On the other hand, only $2(4.8 \%)$ of those with no stressful life events, were depressed. This difference is statistically significant $\left(\mathrm{x}^{2}=15.854 ; \mathrm{df}=2\right.$; $\mathrm{p}=0.000$ ). It can clearly be seen that those respondents with stressful life events that included the death of a child, death of a spouse, marital disharmony and other stressful life events like inability to produce a male child, loss of a job and erectile dysfunction) were significantly more depressed ( $\mathrm{p}=0.000,0.000,0.000$ and 0.021 , respectively). 
Table 4: Relationship between Stressful Life Events and Depression

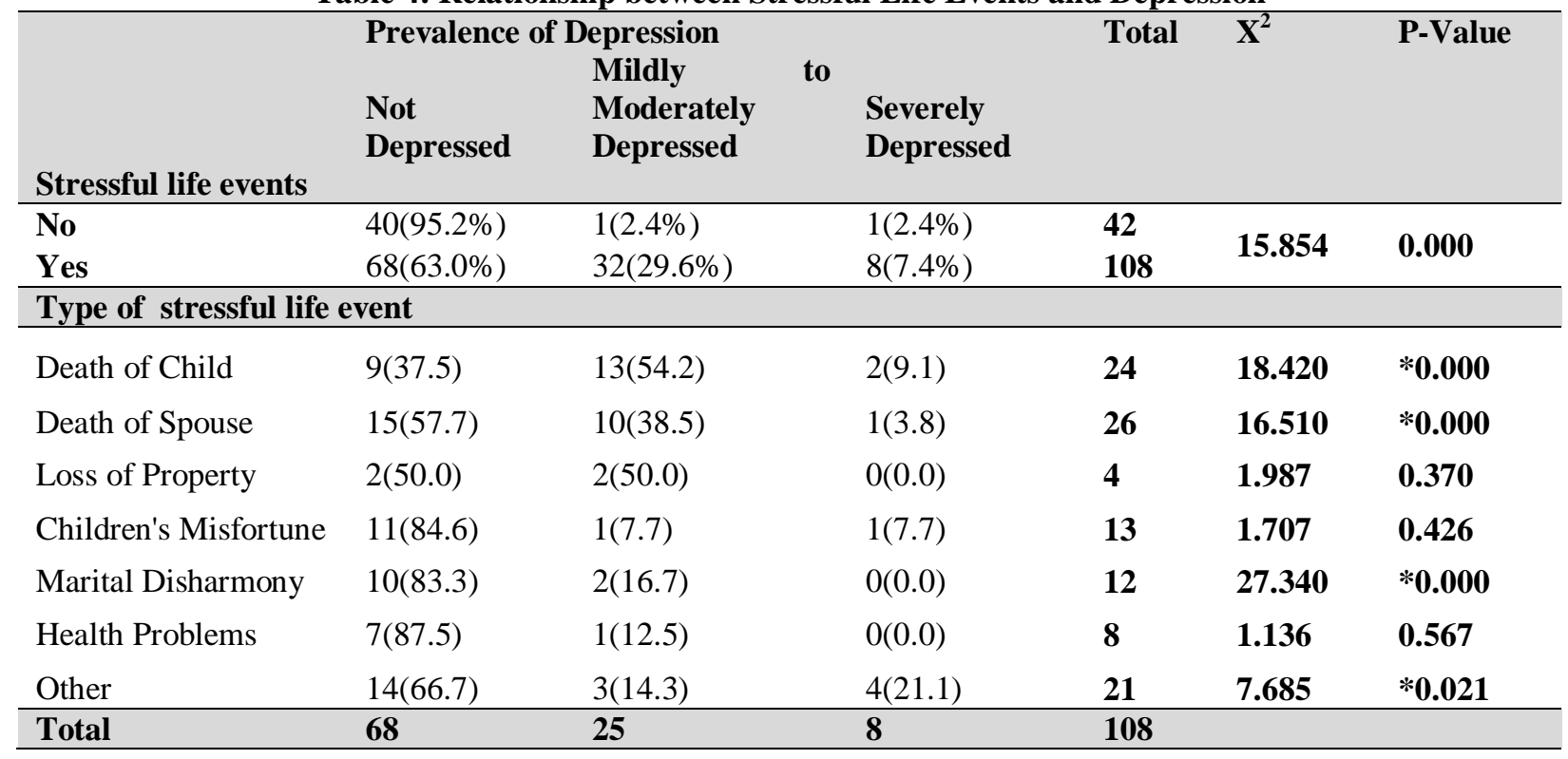

\section{DISCUSSION}

In this study, the overall prevalence of depression in the elderly was found to be $28 \%$ out of which $22 \%$ were mildly to moderately depressed while 6\% were severely depressed Increasing age was found to be a risk factor $(\mathrm{p}=0.000)$. This is in agreement with findings of Papadopoulus et al. ${ }^{35}$ A possible explanation for this could be the fact that the older a person gets, the greater the likelihood of suffering from more age-related degenerative changes, co-morbid conditions and disabilities which are associated with increased prevalence and morbidity of depressive illness. ${ }^{26,27,36}$ This cohort of the elderly is also more likely to be widowed, have low income and poor social support, characteristics which perpetuate depressive illness.

The female sex was found to be a risk factor for depression $(\mathrm{p}=0.002)$. This agreed with the findings of Al-Shammari and Uwakwe ${ }^{37,38}$ A possible explanation could be that most women have a higher average number of co-morbid medical conditions a relatively lower educational background and a higher impact of widowhood than their male counterparts, ${ }^{39}$ both of which are risk factors for depression in the elderly. Women, especially in Africa and particularly in most parts of Nigeria, are the burden-bearers who tend to worry about a myriad of issues bordering on family stability. In the study environment, their major concerns are the welfare of their nuclear and extended families, their sources of income, and their own personal well being. In addition, most of the elderly women had lost their spouses and were widowed. Consequently, the loss of their husbands on whom most of them had solely depended, lead to depletion of their finances and depreciation of their living conditions. Moreover, widowers in the study environment tend to remarry but widows often do not.

Widowhood was also found to be a risk factor for depression in this study $(\mathrm{p}=0.019)$. This is consistent with most other findings. ${ }^{37,3,11,12}$ This could be attributed to lack of social support and decreased income especially on the part of the women, who had lost their breadwinner, who themselves for the most part had little formal education and skills and who, had often been dispossessed of their family belongings by negative cultural practices.

Although the duration of widowhood was not found to have an association with the prevalence of depression $(\mathrm{p}=0.303)$, depression was most prevalent among those who had been widowed for between 1-5 years. The most likely explanation is that the death of their spouses was still fresh on their minds and thus, was a recent psychosocial stressor. Those who had been widowed for 20 years and above formed the next largest group of depressed patients among the elderly widowed subjects. This could be as a result of untold hardship, deprivation and societal neglect they had undergone when they lost their spouses (mostly husbands) at an early age.

The majority of the patients were of a monogamous marital status and the number of spouses had no relationship with depression.

The study population consisted mostly of the Igbos (42\%) most of who resided with their children resident in Port Harcourt. The Ikwerre/Etches formed the next largest group. These are the indigenes of Port Harcourt and its environs. In this study, the Ikwerre/Etches and the Ogonis had a significantly higher prevalence of depression than the Igbos and the Ijaws $(\mathrm{p}=0.000)$. These statistically significant differences in the prevalence of depression could be explained by the fact that cultural beliefs and practices are capable of affecting the perceptions of the nature and causes of illnesses, coping strategies, attitudes towards illness and disease, and 
utilization of health facilities. ${ }^{40}$ From the researcher's interaction with the respondents in this study, the Ijaws were least depressed $(0 \%)$ probably because they were on the average more educated than the respondents from other ethnic nationalities. Furthermore, they as a people are known to be easy going and do not take problems to heart. The Igbo respondents were found to be more motivated and enterprising, exhibited greater adaptability to their environment. This could account for the relatively low prevalence of depression among them $(6.2 \%)$.

Even though $45 \%$ of those that were depressed were unemployed, in this study, unemployment was not found to be a risk factor for depression and the differences in prevalence of depression among the various occupation groups were not found to be significant $(\mathrm{p}=0.129)$. This finding is not consistent with those of $\mathrm{Al}$ Shammari et $\mathrm{al}^{10}$ and Sidik et $\mathrm{al}^{12}$ that implicated unemployment as a risk factor for depression. It could be a reflection of the influence of weightier factors (like female sex, poor family support, widowhood, bereavement) on the prevalence of depression in this group. However, in this study, being a civil servant carried the highest risk $(\mathrm{OR}=10)$. This was followed by unemployment $(\mathrm{OR}=5)$, then self-employment $(\mathrm{OR}=3.96)$ and pensioner $(\mathrm{OR}=1)$. A possible explanation could be that work stress, transportation difficulties, insecurity, high expectations from dependants and inability to meet financial demands in an inflation-ridden economy took a toll on the elderly who were still employed in the civil service. Thus, they were predisposed to depression.

A little over half (53\%) of the patients had no formal education and it is among them the prevalence of depression was highest. In this study, low educational status was found to be a risk factor for depression $(\mathrm{p}=0.002)$. This finding is in agreement with those of Al-Shammari et al ${ }^{10}$, Mills et $\mathrm{al}^{11}$ and Sidik et al. ${ }^{12} \mathrm{~A}$ possible explanation is that education affords people the opportunity to understand their situation in the right perspective against their socio-cultural and economic environment. Therefore, they tend not to worry unnecessarily about potential stressors as they emerge. Furthermore, low educational status is strongly associated with low socio-economic status as those that are poorly educated tend to have less financially rewarding job engagements and therefore are more likely to earn relatively less income than those that are better educated on the average. This in itself is also a risk factor for depression.

A large proportion of the patients (63.4\%) fell into the lower socio-economic classes (Social classes 4 and 5) reflecting a high degree of poverty. The significant association between social status and prevalence of depression $(\mathrm{p}=0.015)$ is in agreement with findings of Kivorkian, Cervilla and Ferreira. ${ }^{1,41,42}$ This is as a result of many factors including inadequate diet, deplorable living conditions, increased propensity to medical illness, decreased ability to procure prescribed drugs and inadequate family support.

Most of the patients depended only on their families for their financial needs (77.3\%). Even though $88 \%$ of the depressed patients fell into this group, there was no association between the sources of income of the respondents and the prevalence of depression in this study $(\mathrm{p}=0.152)$.

Prior history of depression was found to be significantly associated with a higher prevalence of depression $(\mathrm{x} 2=40.291 ; \mathrm{p}=0.000)$. This is in agreement with findings of Krajj et al and Heun et al. ${ }^{3,4}$

In keeping with findings of Al-Shammari et al and Bruce ${ }^{10,2}$, stressful life events were found to be a risk factor for depression $(\mathrm{p}=0.03)$ in this study. Among those who had experienced stressful life events, loss of a child, a spouse, and marital disharmony were found to be risk factors for depression in this study $(\mathrm{p}=0.000$, 0.000 , and 0.021 , respectively). This is in agreement with the findings of Rakel and Bruce. ${ }^{34,2}$

Those that had exercised regularly ( 3 or more times a week) were less likely to suffer from depression than those that had never exercised $(\mathrm{p}=0.001)$. Exercise is known to provide many physical and mental health benefits whereas physical inactivity can lead to deterioration of health. Regular exercise in the form of walking or gardening reduces the incidence, prevalence and morbidity of depression. In addition, those who exercised regularly were less likely to suffer from co-morbidities like diabetes, hypertension, osteoporosis, obesity e.t.c., It is in view of this that exercise is one of the (non-pharmacological) modalities of depression treatment used as an adjunct to pharmacological antidepressant therapy in the elderly. ${ }^{14,44,15}$.

None of the patients admitted to having a positive family history of depression. This could be attributed to misdiagnosis as other explanations could have been given for the depressive symptoms their parents may have had. On the other hand, late onset depression is associated with a lower frequency of family history of depression but a higher frequency of recurrence than in the younger patients. ${ }^{45}$

Prior history of depression was found to be significantly associated with a higher prevalence of depression $(\mathrm{x} 2=40.291 ; \mathrm{p}=0.000)$. This is in agreement with findings of Krajj et al and Heun et al. ${ }^{3,4}$

In keeping with findings of Al-Shammari et al and Bruce ${ }^{37,2}$, stressful life events were found to be a risk factor for depression $(\mathrm{p}=0.03)$ in this study.

Among those who had experienced stressful life events, loss of a child, a spouse, and marital disharmony were found to be risk factors for depression in this study ( $\mathrm{p}=0.000,0.000$, and 0.021 , respectively). This is in agreement with the findings of Rakel and Bruce. ${ }^{34}$

Regular use of antihypertensive agents, antidepressants, anticancer and antidiabetic drugs were found to be risk factors for depressive illness ( $\mathrm{p}=0.033,0.005,0.013$, and0.046 respectively). However, it is not clear whether it 
was the drugs taken or the conditions for which they were taken or both that predisposed these patients to a higher prevalence of depression.

Even though this finding is in agreement with those of Birrer and Evans et $\mathrm{al}^{46,17}$ it would be interesting to know why regular use of the following commonly used drugs (documented as being risk factors for depression in these same studies) were not found to be risk factors for depression in the elderly in this study. These include anxiolytics, tranquilizers, anti-inflammatory and anti-infective agents. Very few subjects were on hormonal agents, anti-psychotic drugs, anticonvulsants and cardiotonic drugs and alcohol. Regular use of the aforementioned drugs was also not found to be a risk factor in this study.

\section{REFERENCES}

[1]. Kevorkian R. Depression in the elderly. Division of Geriatric Medicine, St. Louis School of Medicine. 2005 May (cited 2007 December 12): (screen 1). Available from: www.thedoctorwillseeyounow.com/articles/behaviour/depression

[2]. Bruce ML. Psychosocial risk factors for depressive disorders in late life. Biol Psychiatry, 2002 (52): 175-184.

[3]. Kraaij V, Arensman E, Spinhoven P. Negative life events and depression in elderly persons. The Journals of Gerontology Series B: Psychological Sciences and Social Sciences 2002; 57: 87-94.

[4]. Heun R, Hein S. Risk factors for major depression in the elderly. European Psychiatry 2005; 20 (3): $199-204$.

[5]. Wolters M, Strohle A, Hahn A. Cobalamin: A critical vitamin in the elderly. Preventive Medicine 2004; 39 (6): $1256-1266$.

[6]. Remick RA. Diagnosis and management of depression in primary care; a clinical update and review. Canadian Medical Association Journal 2002; 167 (11): 1253-60.

[7]. Alexopoulos GS, Meyers BS, Young RC, Campbell S, Silbersweig D, Charison M. "Vascular depression" hypothesis. Arc Gen Psychiatry 1997; 54(10): (Abstract).

[8]. Steffen DC, Pieper CF, Bosworth HB, MacFall JR, Provenzale JM, Payne ME, et al. Biological and social predictors of long-term geriatric depression outcome. International Psychogeriatrics 2005; 17: 41-58.

[9]. Gureje, Oye, Ogunniyi, Adesola, Kola, Lola, et al. Functional disability in elderly Nigerians: Results from the Ibadan Study of Ageing: Journal of the American Geriatric Society 2006; 54 (11):1784-1789.

[10]. Al-Shammari SA. Prevalence and correlates of depression among Saudi elderly. Wiley Interscience J;1999: (Abstract).

[11]. Mills TN, Henretta JC. Racial, ethnic and sociodemographic differences in the level of psychosocial distress among older Americans. Research on Ageing 2001; 23 (2): 131-152.

[12]. Sidik SM, Zulkefli NAM, Shah SA. Factors associated with depression among elderly patients in a primary health care clinic in Malaysia. Asia Pacific Family Medicine 2003; 2: 148-152.

[13]. Gazmararian J, Baker D, Parker R, Blazer DG. A multivariate analysis of factors associated with depression. Archives of Internal Medicine 2000; 160 (21): 3307-14.

[14]. Phillips EM, Bodenheimer CF, Roig RL, Cifu DX. Geriatric Rehabilitation.4. Physical medicine and rehabilitation interventions for common age-related disorders and geriatric syndromes.Archives of Physical Medicine and Rehabilitation 2004; 85:18-22.

[15]. Austin EN, Johnston YAM, Morgan LL. Community gardening in a senior centre: A therapeutic intervention to improve the health of older adults. Therapeutic Recreation Journal; 2006 First Quarter: 1.

[16]. Alexopoulos GS. Depression in the elderly. The Lancet 2005; 365 (9475): 1961-1970.

[17]. Evans M, Mottram P. Diagnosis of depression in the elderly patients. Advances in psychiatric treatment 2000; 6: 49-56.

[18]. Walling AD. Prevalence of suicidal ideation in older patients. American Family Physician 2006 (cited 2007 December 10); 73 (4): 1. Available from:http://www.aafp.org/afp/20060215/tips/12.html

[19]. Holley C, Murrel SA, Mast BT. Psychosocial and vascular risk factors for depression in the elderly. Am J Geriatr Psychiatry 2006; 14: 84-90.

[20]. Miller MD, Lenze EJ, Dew MA, et al. Effects of cerebrovascular risk factors on depression; treatment outcomes in later life. Am J Geriatr Psychiatry 2002; 110(5):592-8.

[21]. Pouwer F. Onset and recurrence of depression in older persons Diagnosed with type 2 diabetes: Who is at risk? A prospective study $\begin{array}{lllll}2003-2005 & \text { (cited } & \text { October } & 607 \text { ) } & \text { (Abstract). }\end{array}$ from:http://www.diabetespsychology.nl/abstracts/depressionolderpersons.html

[22]. Nandini V. Perspectives on psycho-neuro-immunology in oncology. Indian J of Palliative Care 2006; 12(1):29-33.

[23]. Baldwin R, Wild R. Management of depression in late life. Advances in Psychiatric Treatment 2004; 10: 131-139.

[24]. Hitti M. Depression may worsen Alzheimer's: Faster mental decline seen in people with history of major depression. Web MD Medical News 2006 (cited 2007 December 2): 1-2. Available from: www.webmd.com

[25]. Williams SA, Kasl SV, Heiat A, Abramson JL, Krumholz HM, Vaccarino V et al. Depression and risk of heart failure among the elderly: A prospective community- based study. Psychosomatic Medicine 2002; 64: 6-12.

[26]. Krishnan KR, Delong M, Kraemer H, Carney R, Spiegel D,Gordon C et al. Co morbidity of depression with other medical diseases in the elderly. Biol. Psychiatry 2002; 52(6): 559-588.

[27]. Gazmararian J, Baker D, Parker R, Blazer DG. A multivariate analysis of factors associated with depression. Archives of Internal Medicine 2000; 160 (21): 3307-14.

[28]. Lawrence V, Murray J, Banerjee S, Turner S, Sangha K, Byng J.et al. Concepts and causation of depression: A cross-cultured study of beliefs of older adults. The Gerontologist 2006; 46: 23-32.

[29]. Coyne JC, Schwenk TL. Diagnosis of late life depression: The View from Primary Care. Biol. Psychiatry 2002; 52 (3): $157-163$.

[30]. Culpepper L. The active management of depression- clinical update. Journal of Family Medicine 2002: 3.

[31]. Press Y. Clinical Trial: Depression and increased health services utilization among elderly primary care patients: Clinical Trials.gov; 2006 (updated 2007 May 24; cited 2007 November 10): 1. Available from:http://www.clinicaltrials.gov/ct/gui/show/NCT00279526

[32]. Conwell Y, Duberstein PR, Caine ED. Risk factors for suicide in later life. Biol. Psychiatry 2002; 52: $193-204$.

[33]. Raj A. Depression in the elderly: Tailoring medical therapy to their special needs. Postgraduate medicine online 2004; 115(6): 1-14.

[34]. Rakel RE. Textbook of Family Practice. 6th ed. Philadelphia: W.B. Saunders; 2002: 91.

[35]. Papadopoulos FC, Petridou E, Argyropoulos S, Kontaxakis V, Dessypris N, Anastasiou A, et al. Prevalence and correlates of depression in late life: A population-based study from a rural Greek town. Int J Geriatr Psychiatry 2005; 20(4): $350-357$.

[36]. Dejonge P, van den Brink RHS, Spijkerman TA, Ormel J. Depressive symptoms in elderly patients after a somatic illness eventprevalence, persistence and risk

[37]. factors. Psychosomatics 2006; 47: 33-42.

[38]. Al-Shammari SA. Prevalence and correlates of depression among Saudi elderly. Wiley Interscience J;1999: (Abstract). 
[39]. Uwakwe R. Psychiatric morbidity in elderly patients admitted to non-psychiatric wards in a General/ Teaching Hospital in Nigeria. Int J Geriatr Psychiatr 2000; 15 (4): 346-354

[40]. Satyarthi K. Global campaign for education issues verdict statement on the education for all high level group communiqué. 2007 (cited 2007 December 9).

[41]. Available from: www.campaignforeducation.org/news/news-full.html

[42]. Marsella AJ. Cultural aspects of depressive experience and disorders. Online Reading in Psychology and Culture 2003; unit 9; ch 4: 1-16.

[43]. Cervilla JA, Prince MJ. Cognitive impairement and social distress as different pathways to depression in the elderly: A crosssectional study. Int J Geriatr Psyciatr 1997;12(10): 995-1000.

[44]. Ferreira M, Kowal P. A minimum data set on ageing and older persons in sub- Saharan Africa: Process and outcome. African Population Studies 2006;21(1):19- 36

[45]. Bruce ML. Psychosocial risk factors for depressive disorders in late life. Biol Psychiatry, 2002 (52): 175-184.

[46]. Mather AS. Effects of exercise on depressive symptoms in older adults with poorly responsive depressive disorder. (Randomized Control Trial) Br J Psychiatry 2002; 180: 411-415.

[47]. Serby M, Yu M. Overview: Depression in the elderly. The Mount Sinai Journal of Medicine 2003; 70(1): 40.

[48]. Birrer RB, Vemuri SP. Depression in late life: A diagnostic and therapeutic challenge. American Family Physician 2004; 69: 237582. 